\title{
Pengaruh Kepemimpinan Terhadap Produktivitas Guru SMP 36 Bandung
}

\author{
Kosasih \\ Universitas Sangga Buana, Bandung, Jawa Barat, Indonesia \\ E-mail: kosasih@usbypkp.ac.id
}

\begin{abstract}
Article Info
Article History

Received: 2021-03-12

Revised: 2021-04-20

Published: 2021-06-02

Abstract

This study aims to determine the effect of leadership on teacher productivity at SMP 36 Bandung. The method used is explanatory research with a sample of 56 respondents. The analysis technique uses statistical analysis with regression, correlation, determination and hypothesis testing. The results of this study of leadership variables obtained an average score of 3.754 with good criteria. The teacher productivity

Keywords:

Leadership;

Productivity; variable obtained an average score of 3.877 with good criteria. Leadership has a positive and significant effect on teacher productivity with the value of the regression equation $\mathrm{Y}=14.712+0.641 \mathrm{X}$, and the correlation coefficient value of 0.764 or has a strong relationship with a determination value of $58.4 \%$. Hypothesis testing obtained a significance of $0.000<0.05$.
\end{abstract}

\begin{tabular}{ll}
\hline Artikel Info & Abstrak \\
\hline Sejarah Artikel & Penelitian ini bertujuan untuk mengetahui pengaruh kepemimpinan terhadap \\
Diterima: 2021-03-12 & produktivitas guru pada SMP 36 Bandung. Metode yang digunakan adalah explanatory \\
Direvisi: 2021-04-20 & $\begin{array}{l}\text { research dengan sampel sebanyak 56 responden. Teknik analisis menggunakan analisis } \\
\text { Dipublikasi: 2021-06-02 } \\
\end{array}$ \\
& $\begin{array}{l}\text { statistik dengan pengujian regresi, korelasi, determinasi dan uji hipotesis. Hasil } \\
\text { penelitian ini variabel kepemimpinan diperoleh nilai rata-rata skor sebesar 3,754 }\end{array}$ \\
Kata kunci: & dengan kriteria baik. Variabel produktivitas guru diperoleh nilai rata-rata skor sebesar \\
Kepemimpinan; & 3,877 dengan kriteria baik. Kepemimpinan berpengaruh positif dan signifikan \\
Produktivitas; & terhadap produktivitas guru dengan nilai persamaan regresi Y = 14,712 + 0,641X, dan \\
Guru. & nilai koefisien korelasi 0,764 atau memiliki tingkat hubungan yang kuat dengan nilai \\
& determinasi 58,4\%. Uji hipotesis diperoleh signifikansi 0,000<0,05.
\end{tabular}

\section{PENDAHULUAN}

Dalam pengembangan bidang ke- pendidikan, tenaga guru sebagai unsur dominan dalam proses belajar mengajar diarahkan untuk meningkatkan kualitas, kompetensi dan profesionalisme. Pencapaian target kompetensi mempunyai maksud untuk membentuk sumber daya manusia yang profesional dan diharap- kan dapat diandalkan, diteladani, memiliki jiwa profesionalisme, sehingga dapat berkompetisi untuk ikut serta membentuk sumber daya manusia berpengetahuan, berketrampilan dan berkemampuan da- lam menyelesaikan tugas dan tanggung jawab pekerjaan dan menghadapi tantangan persaingan hidup (Madrie, 2005:37). Guna memenuhi dan mendapatkan Guru yang kompenten, perlu adanya seleksi penerimaan guru yang memiliki kompetensi kemampuan dan keahlian dalam bidang studi atau mata pelajaran. Kemampuan guru menjadi topik yang perlu dipelajari karena setiap guru tidak hanya bertugas mengajar dalam pengertian mentransformasi pengetahuan kepada murid, melainkan guru juga harus terus berupaya meningkatkan pengetahuannya dan mempraktikkannya. Keberhasilan proses belajar menga- jar dipengaruhi oleh banyak faktor antara lain: guru, siswa, bahan, alat, teknik dan lingkungan. Peran utama guru adalah mendidik dan mengajar yakni menyam- paikan ilmu pengetahuan kepada anak didik, harus memahami tujuan pelajaran, rancangan instruksional secara logis sistematis agar tujuan tercapai secara efektif dan efisien.

Mengajar merupakan kegiatan menyampaikan informasi atau pesan yang mengandung aspek kognitif, aspek afektif dan aspek psikomotorik kepada orang yang belajar, sehingga guru dapat mens- tranfer pesan yang dimilikinya kepada anak didik. Dalam mengorganisasikan kegiatan belajar agar dapat tersusun de- ngan baik, maka guru dapat menuangkan kemampuan profesionalnya sesuai de- ngan kelas, materi, kondisi siswa dan lingkungan belajar. Guruguru Sekolah Menengah Pertama dituntut bertanggung jawab dan konsekuen pada tugas utama nya seperti dalam proses belajar mengajar, memiliki strategi koqnitif yang dapat menumbuhkan kemampuan mengatur, mengelola dan membelajarkan murid agar kreatif. Untuk meningkatkan dan mengembangkan kemampuan yang menggambarkan produktivitas guru, perlu juga dilengkapi dengan fasilitas pembelajaran yang memadai seperti terdapat laboratorium, buku-buku 
referensi atau paling tidak perpustakaan yang lengkap yang dapat digunakan untuk semua sis- wa guna mendukung pelaksanaan pembelajaran.

Upaya meningkatkan produktivitas kerja guru, tidak lepas dari peran kepe- mimpinan kepala sekolah yang merupa- kan sesuatu yang diusahakan harus baik. Kepemimpinan yang baik menggambarkan adanya suasana kekeluargaan dan suasana kerja yang ditandai dengan ada- nya kebebasan berbicara atau mengemu- kakan pendapat, hubungan yang harmo- nis antara guru dengan guru dan antara guru dengan Kepala Sekolah. Hal ini pa- da dasarnya berupa persepsi atau peni- laian guru terhadap kondisi-kondisi terse- but di atas. Guru yang menilai bahwa kepemimpinan kepala sekolah baik, akan merasakan bahwa dirinya dibutuhkan oleh kelompoknya atau institusinya, sehingga akan menimbulkan kesadaran dan rasa tanggung jawab yang tinggi dan lam melaksanakan tugasnya.

Penelitian mengenai pengaruh kepemimpinan terhadap produktivitas kerja sampai saat ini menjadi perhatian para peneliti. Penelitian sebelumnya yang dilakukan oleh Darwito (2008) dan Riska Harjanti (2011) serta Danang Agung Warsiyanto (2011) menunjukkan bahwa kepemimpinan berpengaruh signifikan terhadap produktivitas kerja. Penelitian yang dilakukan oleh Purwo Handoko (2013) menunjukkan bahwa motivasi ber- pengaruh signifikan terhadap produktivitas kerja. Penelitian yang dilakukan oleh Rita Ivana Ariyani menunjukkan bahwa loyalitas karyawan berpengaruh signifikan terhadap produktivitas kerja.

SMP 36 Bandung beralamat Jl. Caringin, Babakan, Kec. Babakan Ciparay, Kota Bandung, Jawa Barat 40222 berstatus sekolah negeri, terdapat berbagai permasalahan di antaranya yang terkait dengan kepemimpinan kepala sekolah, Di samping hal tersebut di atas ke pemimpinan kepala sekolah yang dikem bangkan sangat berpengaruh terhadap produktivitas guru di SMP 36 Bandung. Kepala sekolah merupakan mitra kerja guru yang dapat memotivasi guru sehingga guru dengan sadar dan bertang gung jawab akan tugasnya. Namun pada kenyataannya ada beberapa guru kurang sadar akan tugas dan tanggung jawabnya tanpa pengawasan kepala sekolah.

Pimpinan yang memiliki kemampuan mengelola sumber daya manusia tentunya dapat memimpin lembaganya dengan baik, namun Salah satu tugas kepala sekolah adalah mengelola guru, di mana peran kepala sekolah terhadap produktivitas guru sangatlah penting, apabila kepala sekolah mampu menjalin kerjasama yang baik kepada semua guru, kemungkinan guru akan memiliki produktivitas yang tinggi. Berdasarkan pemaparan di atas, maka penulis membuat judul penelitian "Pengaruh Kepemimpinan Terhadap Produktivitas Guru SMP 36 Bandung", rumusan masalah yang ditetapkan dalam penelitian ini diantaranya:
a. Bagaimana kepemimpinan pada SMP 36 Bandung?

b. Bagaimana produktivitas guru pada SMP 36 Bandung?

c. Adakah pengaruh antara kepemimpinan terhadap produktivitas guru pada SMP 36 Bandung?

\section{METODE PENELITIAN}

Jenis penelitian yang dipakai adalah asosiatif, dimana tujuannya adalah untuk mengetahui atau mencari keterhubungan antara variabel independen terhadap variabel dependennya, dengan Populasi dalam penelitian ini berjumlah 56 responden SMP 36 Bandung, ditetapkan Teknik pengambilan sampling dalam penelitian ini adalah sampel jenuh, dimana semua anggota populasi dijadikan sebagai sampel. Dengan demikian sampel dalam penelitian ini sampel yang digunakan berjumlah 56 responden, dan analisis data digunakan uji validitas, uji reliabilitas, analisis regresi linier sederhana, analisis koefisien korelasi, analisis koefisien determinasi dan pengujian hipotesis.

\section{HASIL DAN PEMBAHASAN}

\section{A. Hasil Penelitian}

\section{1) Analisis Deskriptif}

Pada pengujian ini digunakan untuk mengetahui skor minimum dan maksimum skor tertinggi, ratting score dan standar deviasi dari masingmasing variabel. Adapun hasilnya sebagai berikut:

Tabel 1. Hasil Analisis Descriptive Statistics

\begin{tabular}{lc|c|c|c|c}
\hline \multicolumn{5}{c}{ Descriptive Statistics } \\
\hline & $\mathrm{N}$ & Min & Max & Mean & $\begin{array}{c}\text { Std. } \\
\text { Deviation }\end{array}$ \\
\hline $\begin{array}{l}\text { Kepemi } \\
\text { mpinan } \\
(\mathrm{X})\end{array}$ & 56 & 30 & 49 & 37.54 & 4.112 \\
\hline $\begin{array}{l}\text { Produkti } \\
\text { vitas } \\
\text { Guru (Y) }\end{array}$ & 56 & 30 & 48 & 38.77 & 3.448 \\
\hline $\begin{array}{l}\text { Valid N } \\
\text { (listwise) }\end{array}$ & 56 & & & & \\
\hline
\end{tabular}

Kepemimpinan diperoleh varians minimum sebesar 30 dan varians maximum 49 dengan ratting score sebesar 3,754 dengan standar deviasi 4,112 . Skor ini termasuk pada rentang sakala 3,40 - 4,19 dengan kriteria baik atau setuju.

Produktivitas guru diperoleh varians minimum sebesar 30 dan varians maximum 48 dengan ratting score sebesar 3,877 dengan standar deviasi 3,448 . Skor ini termasuk pada rentang sakala 3,40 - 4,19 dengan kriteria baik atau setuju.

\section{2) Analisis Kuantitatif}

Pada analisis ini dimaksudkan untuk mengetahui pengaruh variabel independen terhadap variabel dependen. Adapun hasil pengujian sebagai berikut:

\section{a. Analisis Regresi Linier Sederhana}

Uji regresi ini dimaksudkan untuk mengetahui 
perubahan variabel dependen jika variabel independen mengalami perubahan. Adapun hasil pengujiannya sebagai berikut:

Tabel 2. Hasil Pengujian Regresi Linier Sederhana

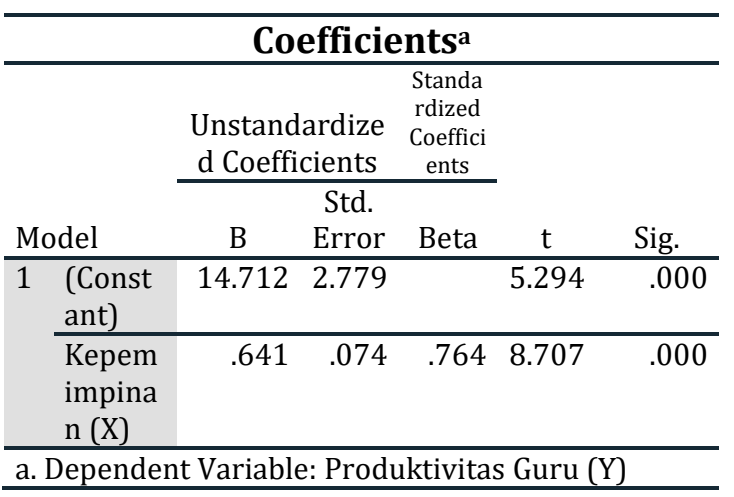

Berdasarkan hasil pengujian pada tabel di atas, diperoleh persamaan regresi $\mathrm{Y}=14,712+$ 0,641X. Dari persamaan tersebut dijelaskan sebagai berikut:

1) Konstanta sebesar 14,712 diartikan jika kepemimpinan tidak ada, maka telah terdapat nilai produktivitas guru sebesar 14,712 point.

2) Koefisien regresi kepemimpinan sebesar 0,641 , angka ini positif artinya setiap ada peningkatan kepemimpinan sebesar 0,641 point maka produktivitas guru juga akan mengalami peningkatan sebesar 0,641 point.

\section{b. Analisis Koefisien Korelasi}

Analisis koefisien korelasi dimaksudkan untuk mengetahui tingkat kekuatan hubungan dari variabel independen terhadap variabel dependen. Adapun hasil pengujian sebagai berikut:

Tabel 3. Hasil Pengujian Koefisien Korelasi Kepemimpinan Terhadap Produktivitas Guru

\section{Correlations $^{b}$}

\begin{tabular}{|c|c|c|c|}
\hline & & $\begin{array}{l}\text { Kepemi } \\
\text { mpinan } \\
(X)\end{array}$ & $\begin{array}{l}\text { Produktivi } \\
\text { tas Guru } \\
(\mathrm{Y})\end{array}$ \\
\hline \multirow{2}{*}{$\begin{array}{l}\text { Kepemi } \\
\text { mpinan } \\
(\mathrm{X})\end{array}$} & $\begin{array}{l}\text { Pearson } \\
\text { Correlation }\end{array}$ & 1 & $.764^{* *}$ \\
\hline & Sig. (2-tailed) & & .000 \\
\hline \multirow{2}{*}{$\begin{array}{l}\text { Produk } \\
\text { tivitas } \\
\text { Guru } \\
(\mathrm{Y}) \\
\end{array}$} & $\begin{array}{l}\text { Pearson } \\
\text { Correlation }\end{array}$ & $.764^{* *}$ & 1 \\
\hline & Sig. (2-tailed) & .000 & \\
\hline
\end{tabular}

**. Correlation is significant at the 0.01 level (2tailed).

b. Listwise $\mathrm{N}=56$

Berdasarkan hasil pengujian diperoleh nilai korelasi sebesar 0,764 artinya kepemimpinan memiliki hubungan yang kuat terhadap produktivitas guru.

\section{c. Analisis Koefisien Determinasi}

Analisis koefisien determinasi dimaksudkan untuk mengetahui besarnya persentase pengaruh dari variabel independen terhadap variabel dependen. Adapun hasil pengujian sebagai berikut:

Tabel 4. Hasil Pengujian Koefisien Determinasi Kepemimpinan Terhadap Produktivitas Guru.

\begin{tabular}{lcccc}
\hline \multicolumn{5}{c}{ Model Summary } \\
\hline Mo & & $\mathrm{R}$ & Adjusted & Std. Error of \\
del & $\mathrm{R}$ & Square & $\mathrm{R}$ Square & the Estimate \\
\hline 1 & $.764^{\mathrm{a}}$ & .584 & .576 & 2.245 \\
\hline a. Predictors: (Constant), Kepemimpinan $(\mathrm{X})$ \\
\hline
\end{tabular}

Berdasarkan hasil pengujian diperoleh nilai determinasi sebesar 0,584 artinya kepemimpinan memiliki kontribusi pengaruh sebesar $58,4 \%$ terhadap produktivitas guru, sedangkan sisanya sebesar $41,6 \%$ dipengaruhi oleh faktor lain yang tidak dilakukan penelitian

\section{d. Uji Hipotesis}

Pengujian hipotesis dengan uji $t$ digunakan untuk mengetahui hipotesis mana yang diterima.

Rumusan hipotesis: Terdapat pengaruh yang signifikan kepemimpinan terhadap produktivitas guru.

Tabel 5. Hasil Uji Hipotesis Kepemimpinan Terhadap Produktivitas Guru.

\begin{tabular}{|c|c|c|c|c|c|}
\hline & & efficie & $n t s^{a}$ & & \\
\hline & $\begin{array}{r}\text { Unstanc } \\
\text { Coeffi }\end{array}$ & $\begin{array}{l}\text { rdized } \\
\text { ients }\end{array}$ & $\begin{array}{c}\text { Stan } \\
\text { dardi } \\
\text { zed } \\
\text { Coeff }\end{array}$ & & \\
\hline Model & B & Error & Beta & $\mathrm{t}$ & Sig. \\
\hline $\begin{array}{ll}1 & \text { (Cons } \\
& \text { tant) }\end{array}$ & 14.712 & 2.779 & & 5.294 & .000 \\
\hline $\begin{array}{l}\text { Kepe } \\
\text { mim } \\
\text { pinan } \\
(\mathrm{X})\end{array}$ & .641 & .074 & .764 & 8.707 & .000 \\
\hline
\end{tabular}

a. Dependent Variable: Produktivitas Guru (Y)

Berdasarkan hasil pengujian pada tabel di atas, diperoleh nilai $\mathrm{t}$ hitung $>\mathrm{t}$ tabel atau $(7,809>$ $2,005)$, dengan demikian hipotesis yang diajukan bahwa terdapat pengaruh yang signifikan atara kepemimpinan terhadap produktivitas guru diterima

\section{B. Pembahasan}

1) Kondisi Jawaban Responden Variabel Kepemimpinan

Berdasarkan jawaban responden, variabel kepemimpinan diperoleh ratting score sebesar 
3,754 berada di rentang skala 3,40 - 4,19 dengan kriteria baik atau setuju.

2) Kondisi Jawaban Responden Variabel Produktivitas Guru

Berdasarkan jawaban responden, variabel produktivitas guru diperoleh ratting score sebesar 3,877 berada di rentang skala 3,40 - 4,19 dengan kriteria baik atau setuju.

3) Pengaruh Kepemimpinan Terhadap Produktivitas Guru

Kepemimpinan berpengaruh signifikan terhadap produktivitas guru dengan persamaan regresi $\mathrm{Y}=$ $14,712+0,641 X$, nilai korelasi sebesar 0,764 atau memiliki hubungan yang kuat dengan kontribusi pengaruh sebesar 58,4\%. Pengujian hipotesis diperoleh nilai $\mathrm{t}$ hitung $>\mathrm{t}$ tabel atau $(7,809>$ 2,005). Dengan demikian hipotesis yang diajukan bahwa terdapat berpengaruh signifikan antara kepemimpinan terhadap produktivitas guru diterima.

\section{SIMPULAN DAN SARAN}

\section{A. Simpulan}

1) Variabel kepemimpinan diperoleh ratting score sebesar 3,754 berada di rentang skala 3,40 4,19 dengan kriteria baik atau setuju.

2) Variabel produktivitas guru diperoleh ratting score sebesar 3,877 berada di rentang skala 3,40 - 4,19 dengan kriteria baik atau setuju.

3) Kepemimpinan berpengaruh signifikan terhadap produktivitas guru dengan persamaan regresi $\mathrm{Y}=14,712+0,641 \mathrm{X}$, nilai korelasi sebesar 0,764 atau kuat dan kontribusi pengaruh sebesar 58,4\% sedangkan sisanya sebesar 41,6\% dipengaruhi faktor lain. Uji hipotesis diperoleh nilai t hitung $>\mathrm{t}$ tabel atau $(7,809>2,005)$.

\section{B. Saran}

Sekolah harus mampu melakukan perbaikan terkait dengan pengupahan dan standar penggajian yang mengacu pada peraturan pemerintah, dan Produktivitas guru dapat ditingkatkan dengan memberdayakan guru dengan menegakkan peraturan yang baik dan pemberian motivasi yang lebih inten lagi..

\section{DAFTAR RUJUKAN}

Algifari. (2015). "Analisis Regresi untuk Bisnis dan Ekonomi". Yogyakarta: BPFE.

Arikunto, Suharsimi (2014). "Prosedur Penelitian Suatu Pendekatan Praktek". Jakarta: Rineka Cipta.

Bangun, Wilson. 2012. "Manajemen Sumber Daya Manusia”. Jakarta: Erlangga
Bejo Siswanto (2013) Manajemen Tenaga Kerja Rancangan dalam Pendayagunaan dan Pengembangan Unsur Tenaga Kerja”, Bandung: Sinar Baru.

Dessler, G. (2006.) Manajemen Sumber Daya Manusia (Jilid II). Jakarta: Indeks.

Edi Sutrisno (2016). Manajemen Sumber Daya Manusia. Jakarta: Prenadamedia Group.

George Terry R \& Rue, Leslie W. Rue (2016) DasarDasar Manajemen, Jakarta Bumi Aksara.

Gerry Dessler (2016) Human Resources Management, Prenticehall, London: International Inc.

Handoko (2016) Manajemen Personalia dan Sumberdaya Manusia. Yogyakarta: BPFE.

Haque, M. G., Munawaroh, M., Sunarsi, D., \& Baharuddin, A. (2021). Competitive Advantage in Cost Leadership and Differentiation of SMEs "Bakoel Zee" Marketing Strategy in BSD. PINISI Discretion Review, 4(2), 277-284.

Hasibuan, Malayu S.P. (2016). Manajemen Sumber Daya Manusia. Edisi Revisi. Jakarta: PT Bumi Aksara.

Hidayat, D. (2020). Pengaruh Kepemimpinan Dan Motivasi Terhadap Kinerja Karyawan Pada PT. Agung Abadi Di Jakarta. JENIUS Jurnal Ilmiah Manajemen Sumber Daya Manusia), 4(1), 22-32.

Hidayat, D., Prabowo, B., \& Anwar, S. (2020). Organizational Leadership and Conflict in Human Resource Management Review. Solid State Technology, 63(6), 1372-1381.

Imam Ghozali (2017). "Aplikasi Analisis Multivariate Dengan Program SPSS". Edisi Kelima. Semarang: Badan Penerbit Undip.

Jasmani, J., \& Paeno, P. (2019). The Effect of Leadership and Competence on Lecturer Performance and Its Implications on Student Learning Motivation at Pamulang University. International Journal of Advances in Social and Economics, 1(4).

Luthans Fred (2014) Organizational Behavior, Ney York: McGraw-Hill, New York.

Mangkunegara, Prabu Anwar. (2016). Evaluasi Produktivitas SDM. Cetakan ke tujuh, PT Refika Aditama: Bandung. 
Marayasa, I. N. (2018). Analisis Kepemimpinan Kepala Desa Sukamulya Kecamatan Rumpin Kabupaten Bogor. JENIUS (Jurnal Ilmiah Manajemen Sumber Daya Manusia), 2(1).

Robbins, P.S, \& Judge, A.T. (2003). Organizational Behavior. Jakarta: Salemba Empat.

Santoso, Singgih (2015). "Menguasai Statistik Multivariat". Jakarta: PT Elex Media Komputindo.

Sedarmayanti (2016) Manajemen Sumber Daya Manusia, Reformasi Birokrasi dan Manajemen Guru Negeri Sipil, Cetakan Kelima, Bandung: PT Refika Aditama.

Sudjana (2014) “Metode Statistika”, Bandung: Tarsido.

Sugiyono (2017), "Metode Penelitian Administrasi : dilengkapi dengan Metode $R \& D$ ". Bandung: Alfabeta.

Sunarsi, D., Rohaeni, . N., Wulansari, . R., Andriani, . J., Muslimat, . A., Rialmi, . Z., Kustini, . E., Kristianti,
. L. S., Rostikawati, . D., Effendy, . A. A., Purwanto, . A. \& Fahlevi, . M. (2020) Effect of eLeadership Style, Organizational Commitment and Service Quality towards Indonesian School Performance. Systematic Reviews in Pharmacy, 11 (10), 472-481. doi:10.31838/srp.2020.10.71

Suryani, N. L. (2018). Pengaruh Gaya Kepemimpinan Dan Motivasi Terhadap Kinerja Karyawan Pada PT. Boga Lestari Sentosa (Kenny Rogers Roasters) Indonesia. JENIUS (Jurnal Ilmiah Manajemen Sumber Daya Manusia), 2(1).

Sutrisno, S. (2019). Pengaruh Kepemimpinan Dan Disiplin Kerja Terhadap Kinerja Guru SMP Muhammadiyah 44 Pamulang. JENIUS (Jurnal Ilmiah Manajemen Sumber Daya Manusia), 3(1), 58-73.

Veithzal Rivai (2015) Manajemen Sumber Daya Manusia Untuk Perusahaan, Jakarta: Raja Grafindo Persada. 